Article

\title{
Experimental Determination of Gas Relative Permeability Considering Slippage Effect in a Tight Formation
}

\author{
Guangfeng Liu ${ }^{1, *(\mathbb{D})}$, Zhaoqi Fan ${ }^{2}$, Yang $\mathrm{Lu}^{3}$, Siying $\mathrm{Li}^{1}{ }^{1}$, Bo Feng ${ }^{1}$, Yu Xia ${ }^{1}$ and Qimeng Zhao ${ }^{1}$ \\ 1 CMOE Key Laboratory of Petroleum Engineering, China University of Petroleum-Beijing, Beijing 102249, \\ China; 2016212591@student.cup.edu.cn (S.L.); 2016212590@student.cup.edu.cn (B.F.); \\ 2016212522@student.cup.edu.cn (Y.X.); 2016212592@student.cup.edu.cn (Q.Z.) \\ 2 Chemical \& Petroleum Engineering, University of Kansas, Lawrence, KS 66045, USA; zhaoqi.fan@ku.edu \\ 3 School of Information Engineering, China University of Geosciences-Beijing, Beijing 100083, China; \\ luyangemail@163.com \\ * Correspondence: lgf@cup.edu.cn; Tel.: 86-10-8973-2192
}

Received: 1 February 2018; Accepted: 19 February 2018; Published: 23 February 2018

\begin{abstract}
In this paper, the gas relative permeability considering slippage effect has been experimentally examined under various experimental conditions (i.e., ambient, high confining pressure, and high temperature). Experimentally, Klinkenberg permeabilities of 12 core samples have been measured by using steady-state flow experiment. It has been found that the Klinkenberg permeability is independent of the experimental temperature and dramatically decreases as confining pressure is increasing. Furthermore, linear correlations have been newly developed between the Klinkenberg permeability and the gas-measured permeability under various conditions. Subsequently, the developed correlations are correspondingly applied to calibrate the gas relative permeability. It has been found that the gas relative permeability can be overestimated without consideration of the slippage effect, i.e., Klinkenberg effect. In addition, the newly developed correlations have been applied to analyze the sensitivity of gas-water relative permeability to gas-measured permeability, confining pressure, and temperature. It is demonstrated that mobile water greatly alleviates the gas relative permeability in comparison to irreducible water. Although an increased confining pressure simultaneously reduces the effective water phase and gas phase permeability, the gas relative permeability increases and the water relative permeability decreases as the confining pressure increases. It is attributed to the fact that the effective water phase permeability is more sensitive to the confining pressure. Given an elevated experimental temperature, the gas relative permeability is reduced while the water relative permeability is enhanced, implying the significance of temperature effect on gas-water relative permeability measurements.
\end{abstract}

Keywords: tight formation; slippage effect; Klinkenberg permeability; gas relative permeability; pore-throat structure

\section{Introduction}

Natural gas plays an increasingly significant role in world energy supply of modern economy since fossil fuels, e.g., petroleum fluids and coal, readily trigger on environmental issues, e.g., air pollution and excessive greenhouse gas emissions [1]. Alternatively, natural gas serves as a much cleaner energy with zero solid particle emission and lower waste gas production. The gas production from tight formations is dramatically booming due to prominent improvements in hydraulic fracturing and horizontal drilling [2,3]. It has been addressed that tight gas production has increased from $11 \%$ in 1990 to $18 \%$ in 2003 of total U.S. natural gas production while, by $2010,24.6 \%$ of the produced 
natural gas originated from the tight gas formations in China $[4,5]$. Conceptually, the recovery of a tight gas reservoir is significantly dominated by the flow capacity of gas and water. In practice, the gas production is substantially impacted by the presence of water production, especially for the late stage of the gas reservoir development. Since the relative permeability is commonly used to represent the characteristic of pore structures, saturation distribution, and wettability of the tight formation, the gas-water relative permeability has been used to demonstrate the relative flow capacity of gas and water in tight formations. Therefore, it is of significant importance to examine the gas-water relative permeability under various conditions for better understanding the underlying mechanisms of gas flow in tight formations.

The gas-water relative permeability in tight formation has attracted substantial attention in past decades [6-10]. Numerous efforts have been made to theoretically and experimentally estimate the gas-measured permeability and the gas relative permeability conditioned to slippage effect [11-16]. In the laboratory, the gas-water relative permeability can be determined by either steady-state or unsteady-state flow experiments [7,14,17]. Rushing et al. (2003) addressed that the gas relative permeability may be overestimated if the two-phase gas slippage, i.e., Klinkenberg effect, was not considered in the laboratory experiments. Moreover, the confining pressure and water saturation dramatically affect both the gas phase permeability and gas relative permeability $[18,19]$. In addition, Walls et al. (1982) have demonstrated that accurate acquaintance of in situ fluid saturation is crucial before gas production rates can be estimated. They also indicated that confining pressure might result in significant permeability reduction according to observations in sandstones from Spirit River formation of Alberta, Canada [20]. Furthermore, it was indicated that the Klinkenberg-corrected permeability, thereafter called absolute permeability in this paper, is independent of temperature, although the Klinkenberg slippage factor is linearly proportional to the experimental temperature [21,22].

The quantification of the slippage effect on gas-measured permeability is a time-consuming process, especially when high pressure and escalated temperature are involved. The unsteady-state pressure-fall-off technique has been applied to greatly reduce the measurement duration by using toluene as wetting phase and nitrogen as non-wetting phase, respectively [10]. The slippage effect can be moderately reduced by exerting a back-pressure at the outlet of the core samples [16]. It was also demonstrated that the slippage effect may be eliminated while the back-pressure rise to a specific back-pressure and thus the non-slippage gas-measured permeability can be experimentally determined. However, the high pressure may be involved in the experimental apparatus while the core samples are sufficiently tight, resulting in more difficulties of conducting displacement experiments. As such, it is imperative to find a method of efficiently and accurately determining the gas-water relative permeability conditioned to slippage effect.

In this paper, the gas-water relative permeability considering slippage effect has been experimentally examined under various experimental conditions (i.e., ambient, high confining pressure, and high temperature). More specifically, steady-state flow experiments have been conducted to establish correlations between the Klinkenberg permeability and gas-measured permeability under the aforementioned experimental conditions. Subsequently, the developed correlations are applied to correct the effective gas phase permeability for calibrating the gas-water relative permeability. In addition, the sensitivity of calibrated gas-water relative permeability to gas-measured permeability, confining pressure, and temperature have also been demonstrated by use of the unsteady displacement experiments for the purpose of reducing experimental time.

\section{Experimental}

\subsection{Core Samples Preparation}

Core samples have been collected from two adjacent wells in a tight gas reservoir located in the Ordos Basin, China. The depth of payzone is ranging from $3200 \mathrm{~m}$ to $3400 \mathrm{~m}$. The original fluid pressure of the reservoir is approximately $25.00 \mathrm{MPa}$, implying that it is a low-pressure reservoir. 
The reservoir temperature ranges from $90{ }^{\circ} \mathrm{C}$ to $110{ }^{\circ} \mathrm{C}$. To simulate reservoir conditions in the laboratory, the experimental temperature is set to be between $25^{\circ} \mathrm{C}$ to $90^{\circ} \mathrm{C}$ while the experimental confining pressure is ranging from $2.35 \mathrm{MPa}$ to $50.00 \mathrm{MPa}$.

The gas-measured permeability, porosity, and geometrical parameters of 17 core samples used in following experiments have been listed in Table 1. Diameters of those core samples are varying from $2.508 \mathrm{~cm}$ to $2.521 \mathrm{~cm}$, while their lengths are between $6.668 \mathrm{~cm}$ and $7.452 \mathrm{~cm}$. Geometrical similarities of the core samples are anticipated to reduce the probable uncertainties with respect to scale differences. It is worth pointing out that the gas-measured permeability in Table 1, i.e., $k_{g}^{*}$, was measured by using gas (i.e., nitrogen) under laboratory conditions.

Table 1. Properties of 17 core samples collected from the tight gas reservoir

\begin{tabular}{cccccc}
\hline Group No. & Core No. & $\boldsymbol{k}_{\boldsymbol{g}}^{*} \mathbf{m} \mathbf{m D}$ & Porosity, $\%$ & Length, $\mathbf{c m}$ & Diameter, $\mathbf{c m}$ \\
\hline & $\# 1$ & 0.0535 & 7.12 & 6.942 & 2.511 \\
& $\# 2$ & 0.3427 & 12.39 & 7.215 & 2.517 \\
& $\# 3$ & 0.2046 & 7.81 & 6.872 & 2.515 \\
& $\# 4$ & 0.4264 & 10.97 & 6.928 & 2.509 \\
Group \#1 & $\# 5$ & 0.1371 & 8.35 & 6.927 & 2.512 \\
& $\# 6$ & 0.4327 & 9.21 & 7.237 & 2.513 \\
& $\# 7$ & 0.0952 & 4.45 & 7.452 & 2.516 \\
& $\# 8$ & 0.1464 & 8.10 & 6.844 & 2.514 \\
& $\# 9$ & 0.3010 & 9.81 & 6.738 & 2.512 \\
& $\# 10$ & 0.0511 & 5.85 & 7.328 & 2.521 \\
& $\# 11$ & 0.0929 & 7.36 & 6.924 & 2.512 \\
& $\# 12$ & 0.3058 & 9.89 & 6.668 & 2.514 \\
\hline \multirow{6}{*}{ Group \#2 } & $\# 13$ & 0.1418 & 7.06 & 7.076 & 2.514 \\
& $\# 14$ & 0.2986 & 7.97 & 6.786 & 2.508 \\
& $\# 15$ & 0.7312 & 8.18 & 7.452 & 2.516 \\
& $\# 16$ & 2.8730 & 13.61 & 7.084 & 2.516 \\
& $\# 17$ & 0.2280 & 5.79 & 6.766 & 2.512 \\
\hline
\end{tabular}

Regarding the porosity, its measurement follows 5 steps: (1) Dry the core samples under $110{ }^{\circ} \mathrm{C}$ for $8 \mathrm{~h}$ aiming to deprive connate water of the core samples for improving the accuracy of porosity measurement; (2) Weight the dried core samples; (3) Vacuum the core samples; (4) Saturate the vacuumed core samples with synthetic brine and weight the wet core samples; (5) Calculate the porosity by use of weight difference between the dry and wet core samples.

Note that 17 core samples have been divided into two groups. Group \#1 including 12 core samples was used to quantify the Klinkenberg permeability under ambient condition, high-temperature (HT) condition, and high-temperature-high-confining-pressure (HTHCP) condition. As for the ambient condition, the confining pressure $\left(p_{c p}\right)$ is approximately $2.0 \mathrm{MPa}$ higher than the mean pressure over the core sample (see GB/T 29172-2012). Given various mean pressure, the measured gas permeability changes as well. Group \#2 including 5 core samples was utilized to evaluate sensitivities of calibrated gas-water relative permeability to $k_{g}$, confining pressure, and temperature with the consideration of the slippage effect.

\subsection{Fluid Preparation}

Synthetic brine with a concentration of $8.0 \mathrm{wt} \%$ has been prepared by dissolving potassium chloride $(\mathrm{KCl})$ into deionized water to reach the same salinity as the formation water. This was to reduce the probability of permeability reduction resulted from reactions between injected water and the reservoir rock. In addition, the nitrogen of $99.999 \%$ purity has been used as a gas phase in displacement experiments.

\subsection{Apparatus}

The apparatus has been illustrated in an experimental flowchart as shown in Figure 1. A temperature control system with a range of $25.0^{\circ} \mathrm{C}$ to $200.0^{\circ} \mathrm{C}$ and an accuracy of $\pm 0.2{ }^{\circ} \mathrm{C}$ has been used to control the experimental temperature (see (17) in Figure 1). As for high-temperature 
experiments, a tubing with a length of $4.0 \mathrm{~m}$ and an inner diameter of $0.003 \mathrm{~m}$ has been placed in the temperature control system for transporting and heating the gas (i.e., nitrogen). The rest includes a core holder, cylinders (capacity of $100 \mathrm{~mL}$, service pressure of $50.00 \mathrm{MPa}$ ), syringe pumps (100DX, Teledyne Isco Inc., Lincoln, NE, USA), pressure transducers (maximum of 69,000.00 kPa; accuracy of $\pm 0.01 \mathrm{kPa}$ ), gas mass flow controller (0-200 sccm with the accuracy of $\pm 0.2 \%$ F.S, Porter, Hatfield, PA, USA), gas mass flow meters (50 sccm with the accuracy of $\pm(0.8 \%$ Rdg $+0.2 \% \mathrm{~F} . S)$, ALICAT, Tucson, AZ, USA), and a high-pressure and high-temperature viscometer (VISCOlab PVT, CVI, Boston, MA, USA) with a measurable range of $0.02-10,000.00 \mathrm{cP}$ and an accuracy of $\pm 1.0 \%$ FS. The allowable pressure and temperature of the viscometer are $0-138,000.00 \mathrm{kPa}$ and the temperature up to $190{ }^{\circ} \mathrm{C}$, respectively. In addition, the gas humidifier was used to avoid the vaporization of water in the core samples during the displacement experiments.

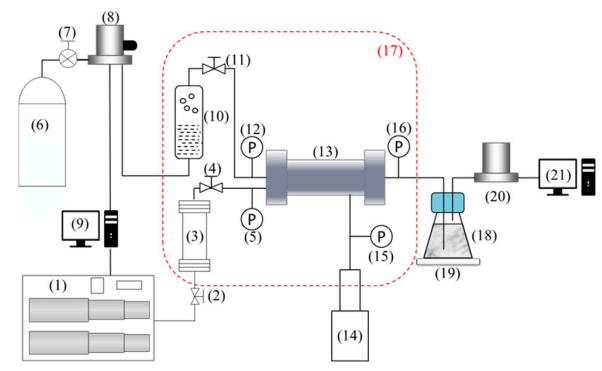

Figure 1. Schematic diagram of experimental apparatuses: (1) Syringe pump; (2), (4), (11) Valve; (3) Synthetic brine cylinder; (5), (12), (15), (16) Pressure transducer; (6) Nitrogen cylinder; (7) High pressure reducing valve; (8) Gas mass flow controller; (9), (21) Data acquisition system; (10) Gas humidifier; (13) Core holder; (14) Confining pressure pump; (17) Electric heating thermostat; (18) Dryer; (19) Balance; and (20) Gas mass flow meter.

The produced water was measured by using an analytical balance (ME 204, Sao Viet Technologies Co. Ltd., Ho Chi Minh City, Vietnam) with a maximum capacity of $220 \mathrm{~g}$ and an accuracy of $0.0001 \mathrm{~g}$. The water saturation in the core samples can be accordingly calculated with the measured weight of the produced water. Moreover, the mentioned gas mass flow meter has been used to measure the produced gas flow rate. The image of the whole experimental system has been illustrated in Figure 2 .

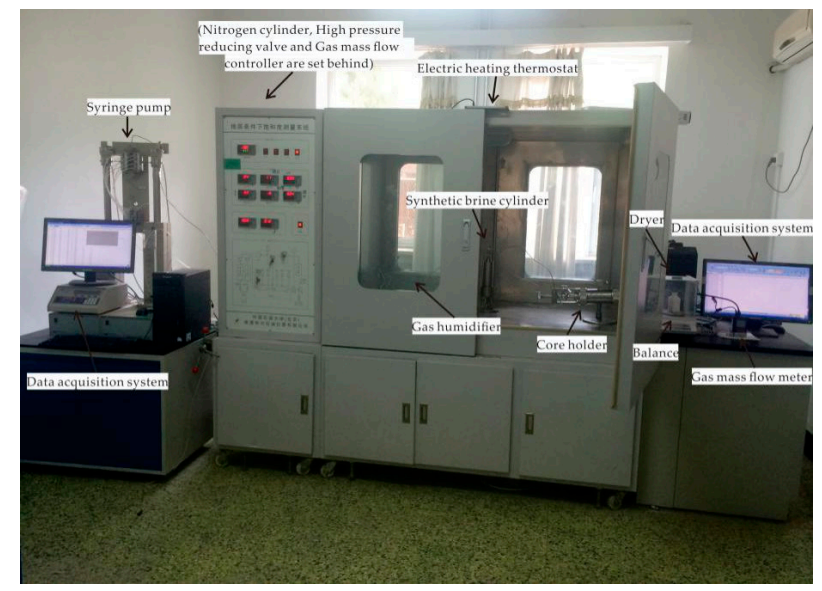

Figure 2. Image of displacement experiment system.

\subsection{Experimental Procedure}

In this section, steady-state and unsteady-state flow experiments have been used to measure the Klinkenberg permeability and investigate the slippage effect on gas-water relative permeability, 
respectively. In an attempt to achieve steady-state flow, the pressure at inlet and outlet and the flow rate at the outlet are necessary to be stable for $30 \mathrm{~min}$ for each measurement point. Injection pressure and confining pressure were simultaneously increasing when average pressure over the core samples was required to be raised, or vice versa. Regarding Klinkenberg permeability measurements under HT condition, the core samples were required to be heated for five hours at a given temperature (i.e., $90^{\circ} \mathrm{C}$ ) in the temperature control system. The heating process is to guarantee that the temperature of core samples can reach $90{ }^{\circ} \mathrm{C}$ prior to the measurements. In addition, the gas viscosity used in the permeability calculation was required to be correspondingly adjusted with respect to the experimental temperature since the gas viscosity would increase as elevated temperature as shown in Figure 3a. In contrast, the viscosity of the synthetic brine rarely changes with temperature as shown in Figure $3 b$. As for HTHCP Klinkenberg permeability measurements, the confining pressure would be gently increased to eliminate the effect of stress sensitivity.

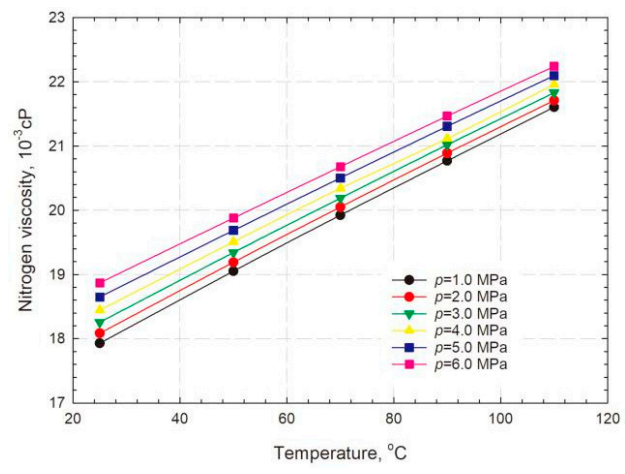

(a)

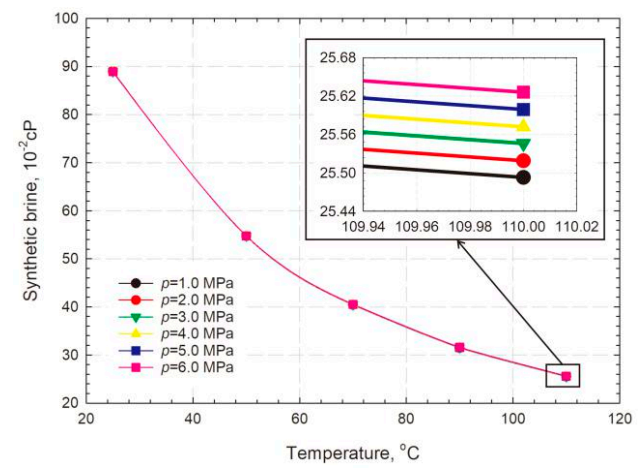

(b)

Figure 3. Sensitivity of (a) nitrogen and (b) synthetic brine viscosity to pressure and temperature.

By taking two-phase displacement experiments as an example, the detailed procedures of the steady-state flow experiments have been introduced as follows:

(1) Prepare the synthetic brine and nitrogen as mentioned in Section 2.2, and inject the synthetic brine into the cylinder;

(2) Vacuum the core sample for $12 \mathrm{~h}$ and saturate it by injecting synthetic brine into it under $30.0 \mathrm{MPa}$ for $12 \mathrm{~h}$;

(3) Place the saturated core sample into the core holder and increase experimental temperature through the temperature control system to programmed temperature. Confining pressure has also been loaded in this step since the confining pressure is crucial for accurately estimating reliable permeability of tight sandstone under reservoir conditions [20];

(4) Inject the synthetic brine until the injected pressure is stable and record the pressure at the inlet and outlet of the core sample as well as the rate of produced liquid for determining absolute permeability of the core sample;

(5) With an outlet pressure of $0.10 \mathrm{MPa}$, the nitrogen is injected until no more brine is produced and the gas flow rate and injection pressure are recorded for calculating the effective gas permeability at an irreducible water saturation $\left(S_{w i}\right)$. As such, the endpoints of the relative permeability curve, i.e., $\left[S_{w i}, k_{r g}\left(S_{w i}\right)\right]$ and $\left[S_{w i}, k_{r w}\left(S_{w i}\right)=0\right]$, can be obtained;

(6) By considering the injection pressure being less than 4.50 MPa (see GB/T 28912-2012), the synthetic brine and gas with specific rate ratio are injected until the flow is stable. Two criteria are employed to determine whether the stable flow is reached or not: (a) injection pressure at the inlet keeps steady and (b) the gas flow rate at the outlet is constant;

(7) After the stable state is reached, the injection pressure, gas, and water flow rate are recorded for determining the corresponding effective gas phase and water phase permeability, respectively. 
Note that the gas and water viscosity, used in Equations (2) and (3), is dynamically varied according to experimental pressure and temperature as shown in Figure 3a,b. The water saturation at current circumstance can be determined by weighting the produced water volume. In this case, two points, i.e., $\left[S_{w j}, k_{r w}\left(S_{w j}\right)\right]$ and $\left[S_{w j}, k_{r g}\left(S_{w j}\right)\right](j=1)$, on the relative permeability curves can be obtained;

(8) More points, i.e., $\left[S_{w j}, k_{r}\left(S_{w j}\right)\right](j=2,3, \ldots, n)$, on the gas-water relative permeability curves can be determined by dynamically changing the ratio of water flow rate to gas flow rate and repeating Steps 6-7; and,

(9) Terminate the experiment when gas relative permeability is less than 0.005 (see GB/T 28912-2012).

Since the steady-state displacement experiments are time-consuming, unsteady-state displacement experiments have been conducted to analyze the sensitivities of the gas-water relative permeability to $k_{g}$, confining pressure, and temperature. The pre-processing of the unsteady-state displacement experiments is identical to that of the steady-state displacement experiments. In another word, Steps $1-3$ in the procedure of the steady-state displacement experiments can be inherited and also used in the unsteady-state displacement experiments. After Steps 1-4, the procedure of the unsteady-state experiments follows: (a) inject the nitrogen using the same injection pressure of the synthetic brine as that in the previous step; (b) record the pressure at the inlet and outlet of the core samples, the volume of produced liquid with equal time intervals during the displacement processes; and (c) terminate the displacement experiments until there is no more brine produced from the core samples.

\subsection{Determination of Relative Permeability}

With the measured data of steady-state and unsteady-state displacement experiments, the gas-water relative permeability can be numerically calculated. The water saturation is obtained by

$$
S_{w j}=\frac{m_{j}-m_{o}}{m-m_{o}} \times 100 \%
$$

where $S_{w j}$ represents the water saturation under a certain condition, $j=1,2, \ldots, n, ; m$ is the total mass of wet core sample saturated with any synthetic brine, $g$; $m_{0}$ is the mass of dry core sample, $g$; $m_{j}$ indicates the mass of wet core sample under a certain condition, g. Note that the dynamic mass of the wet core samples can be obtained by subtracting the total mass of the wet core samples by the mass of produced synthetic brine. The gas saturation can be readily achieved with known water saturation since the sum of them is equal to 1.0.

The effective permeability of gas and water phase can be respectively calculated by Li and Horne (2001) [22]

$$
\begin{aligned}
& k_{e g}=\frac{2 p_{a} q_{g} \mu_{g} L}{A\left(p_{1}^{2}-p_{2}^{2}\right)} \times 10^{3} \\
& k_{e w}=\frac{q_{w} \mu_{w} L}{A\left(p_{1}-p_{2}\right)} \times 10^{3}
\end{aligned}
$$

where $k_{e g}$ is the effective gas phase permeability measured with nitrogen, $\mathrm{mD} ; k_{e w}$ is the effective water phase permeability, $\mathrm{mD} ; p_{a}$ indicates atmosphere pressure, $0.1 \mathrm{MPa} ; q_{g}$ represents the gas flow rate, $\mathrm{mL} / \mathrm{s} ; \mu_{g}$ is the gas viscosity under experimental conditions, $\mathrm{cP} ; L$ is the core sample length, $\mathrm{cm} ; A$ is the cross area of core sample, $\mathrm{cm}^{2} ; p_{1}$ indicates the pressure at inlet of core sample, $0.1 \mathrm{MPa} ; p_{2}$ indicates the pressure at outlet of core sample, $0.1 \mathrm{MPa} ; q_{w}$ represents the water flow rate, $\mathrm{mL} / \mathrm{s} ; \mu_{w}$ is the water viscosity under experimental conditions, $\mathrm{CP}$. Considering dynamic fluid pressure and temperature during the experiments, the dependence of fluid viscosity on pressure and temperature have been experimentally measured and shown in Figure 3. It is worthwhile to point out that the synthetic brine viscosity is independent of pressure while the nitrogen viscosity can be slightly increased with increasing pressure at a given temperature. With respect to the pressure and temperature conditions in 
the experiments, the corresponding fluid viscosity can be determined, which can be used to calculate the effective gas and water phase permeability using Equations (2) and (3). Subsequently, the gas-water relative permeability can be achieved as

$$
\begin{aligned}
& k_{r g}\left(S_{w j}\right)=\frac{k_{e g}\left(S_{w j}\right)}{k_{a b s}} \\
& k_{r w}\left(S_{w j}\right)=\frac{k_{e w}\left(S_{w j}\right)}{k_{a b s}}
\end{aligned}
$$

where $k_{r g}$ is the gas relative permeability; $k_{r w}$ represents the water relative permeability; $k_{a b s}$ indicates the absolute permeability measured by using synthetic brine, $\mathrm{mD}$. As demonstrated in Equations (4) and (5), the absolute permeability has been used to normalize the gas-water relative permeability for the core samples.

\section{Results and Discussions}

\subsection{New Correlations: $k_{s}$ vs. $k_{g}$}

Considering the slippage effect associated with gas flow in tight formation, Klinkenberg (1941) proposed an equation to correlate the gas-measured permeability $\left(k_{g}\right)$ under different mean pressure over the core samples $\left(p_{m}\right)[11]$.

$$
k_{g}=k_{s}\left(1+\frac{b}{p_{m}}\right)
$$

where $k_{s}$ is the Klinkenberg permeability of core samples, $\mathrm{mD} ; b$ is the slippage factor, its unit depends on the unit of the mean pressure; $p_{m}$ is mean of pressures at two ends of the core sample. Equation (6) has demonstrated that the Klinkenberg permeability is linearly related to the reciprocal of mean pressure, i.e., $1 / p_{m}$.

Considering high temperature and high effective stress of tight reservoirs, the Klinkenberg permeabilities of core samples \#1-8 have been respectively examined under three experimental conditions including ambient condition, HT condition $\left(p_{c p}=2.35 \mathrm{MPa}, T=90\right)$, and HTHCP condition $\left(p_{c p}=30.00 \mathrm{MPa}, T=90\right)$. The Klinkenberg permeabilities of core samples \#9-12 in Table 1 have been measured under ambient conditions. The experimental results of the core samples \#1-6 under the ambient, HT, and HTHCP conditions have been used as examples and illustrated by circles, triangles, and squares in Figure 4, respectively. According to Equation (6), the interception of the regression curves on the vertical coordinates is corresponding to the Klinkenberg permeability. The slope of the regression curves moderately represents the magnitude of the slippage factor since the slope is equal to $k_{s} \times b$ and the $k_{s}$ is a constant.

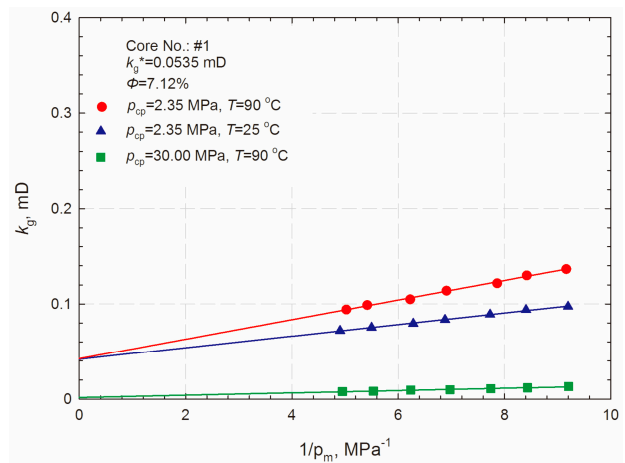

(a)

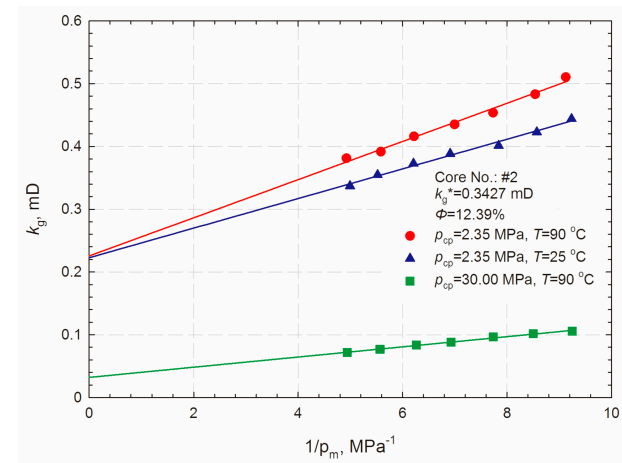

(b)

Figure 4. Cont. 


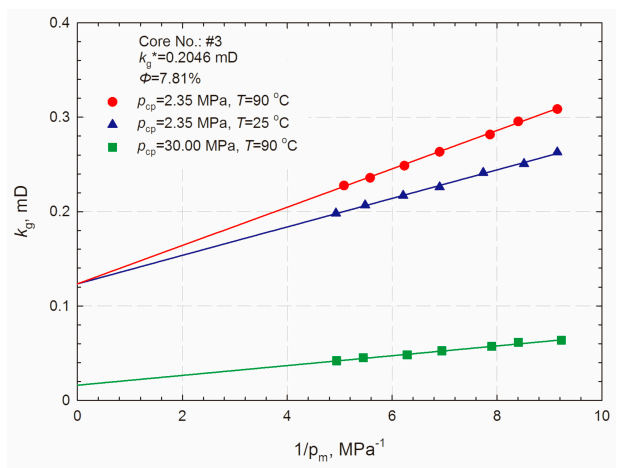

(c)

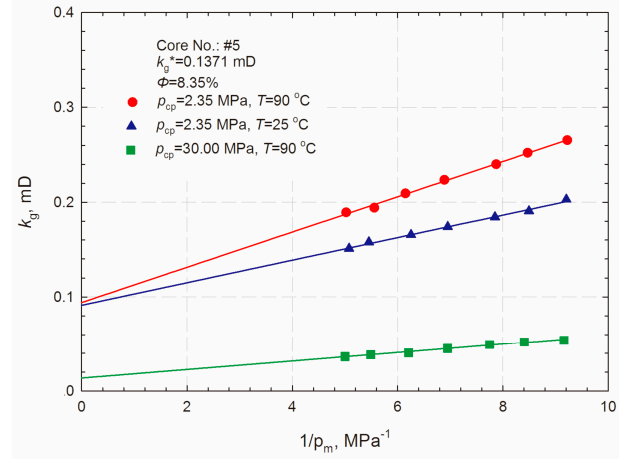

(e)

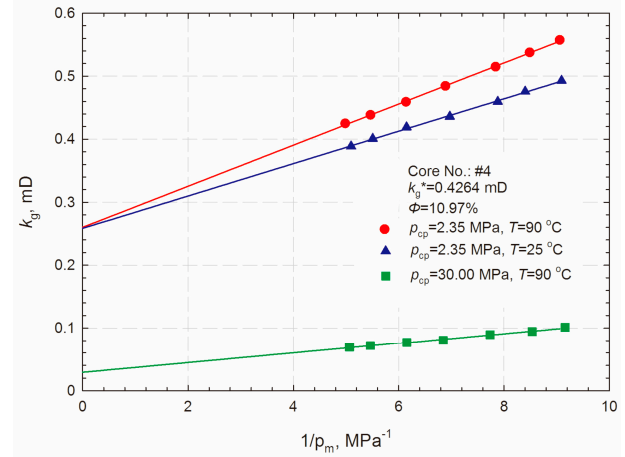

(d)

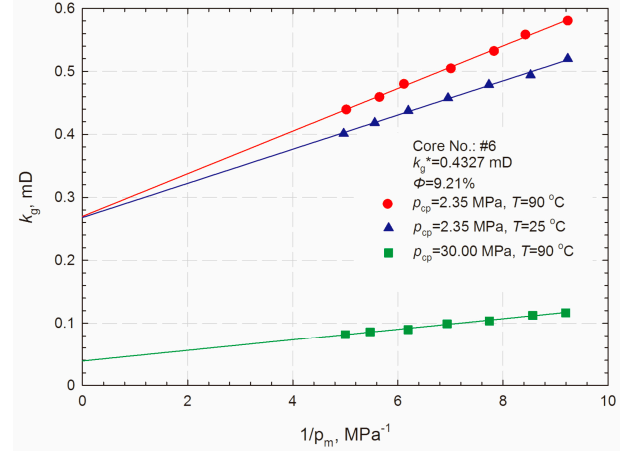

(f)

Figure 4. Experimental results of Klinkenberg correction for core samples: (a) \#1; (b) \#2; (c) \#3; (d) \#4; (e) \#5; (f) \#6.

It can be found that good linear relationships are associated with the experimental data shown in Figure 4. Moreover, the comparison of experimental results under the ambient and HT conditions has revealed that the Klinkenberg permeability is independent of the experimental temperature while the slippage factor increases as elevated temperature. In addition, the gas-measured permeability increases when the experimental temperature is escalated. This is attributed to the fact that the raised temperature contributes to the increased mean free path of the gas, which is positively proportional to the gas-measured permeability. Furthermore, the effect of temperature on the gas-measured permeability is distinctly strengthened as the absolute permeability decreases. Such findings are corresponding to experimental results reported in the literature [21,22]. In comparison to the temperature, the increasing confining pressure affects both the Klinkenberg permeability and the slippage factor. In addition, the Klinkenberg permeability has been dramatically reduced with an increased confining pressure since intense compression collapses partial pores and throats inside the core samples, which also contributes to the inhibited slippage factor.

Besides the previous findings associated with the Klinkenberg permeability and the slippage factor, the Klinkenberg permeability has been found to be linearly related to the $k_{g}$ under the aforementioned three experimental conditions, which shares similarity with the Klinkenberg permeability measured in tight oil formations [23]. Figure 5 shows the relationships between $k_{g}^{*}$ and Klinkenberg permeability of samples 1-12 and samples 1-8 under high confining pressure condition, respectively. Because the Klinkenberg permeability is independent of the temperature, the squares in Figure 5 represent the relationship between the Klinkenberg permeability and $k_{g}^{*}$ under both of ambient and high-temperature conditions. A similarly linear relationship under high confining pressure conditions has been depicted as circles in Figure 5. Since $k_{g}^{*}$ represents the $k_{g}$ under a specific condition, the linear correlation under specific conditions can be generally represented by a mathematical formulation

$$
k_{s}=0.5915 k_{g}, R^{2}=0.9423
$$


Equation (7) can moderately represent the permeability characteristic of the formation surrounding the aforementioned tight gas wells. Such a relationship provides a convenient way to estimate the Klinkenberg permeability with given $k_{g}$. As for the high confining pressure condition, the linearity among the circles in Figure 5 can be expressed by

$$
k_{s}=0.0914 k_{g}, R^{2}=0.9018
$$

The relatively small slope in Equation (8) has demonstrated that the changes of $k_{g}$ resulted from the increased confining pressure are much larger than that induced by the escalated temperature. From a microscopic point of view, the increased confining pressure is prone to collapse partially interconnected pores that are the main contributions of the permeability. It is interesting that the linear relationship between the Klinkenberg permeability and $k_{g}$ has been well maintained for various experimental conditions. In other words, such a linear correlation might be an intrinsic property of the core samples, although the coefficients of this correlation depend on the experimental conditions.

The significances of Equations (7) and (8) are that the Klinkenberg permeability of core samples can be readily determined, provided that the coefficients of them can be preliminarily obtained by using representative core samples in the same area. As for the gas-water flow, the convenient and accurate description of how to calibrate the effective gas phase permeability involving the slippage effect is still unavailable. Now, Equations (7) and (8) can be applied to calibrate the effective gas phase permeability measured in the experiments determining gas-water relative permeability, although they are achieved in single-phase flow experiments.

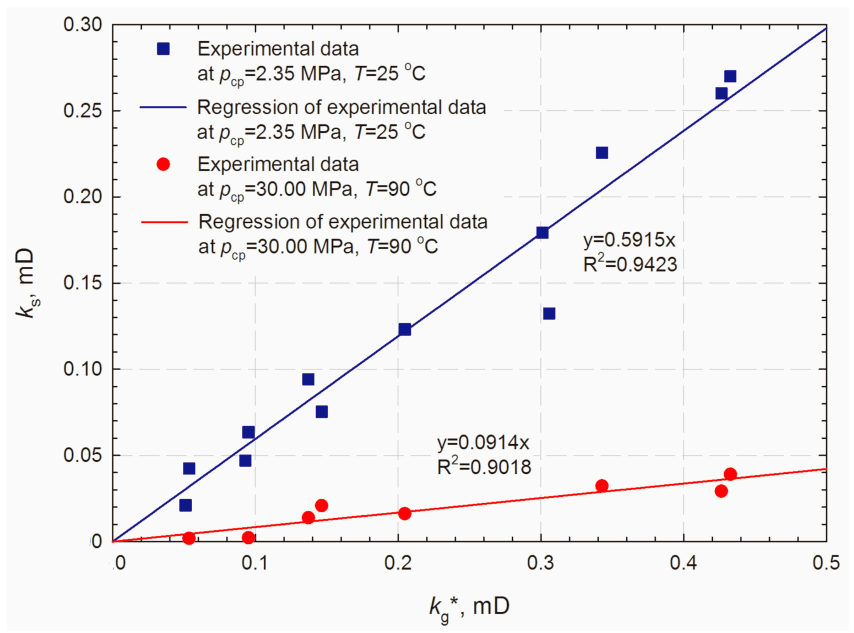

Figure 5. Correlations between the Klinkenberg permeability and $k_{g}^{*}$ under different conditions.

\subsection{Calibration of Gas Relative Permeability}

The gas-water relative permeability has been measured for the core sample \#4 by using the steady-state displacement experiments under the ambient condition. More specifically, a confining pressure of $2.35 \mathrm{MPa}$ was applied during the displacement process while the outlet was constrained by a pressure of $0.10 \mathrm{MPa}$. With the measured pressure and production data, the gas-water relative permeability of core sample \#4 has been obtained through Equations (2)-(5) and depicted in Figure 6. To minimize the effect of singular points measured during experiments, regression curves are used to present the variation of relative permeabilities. 


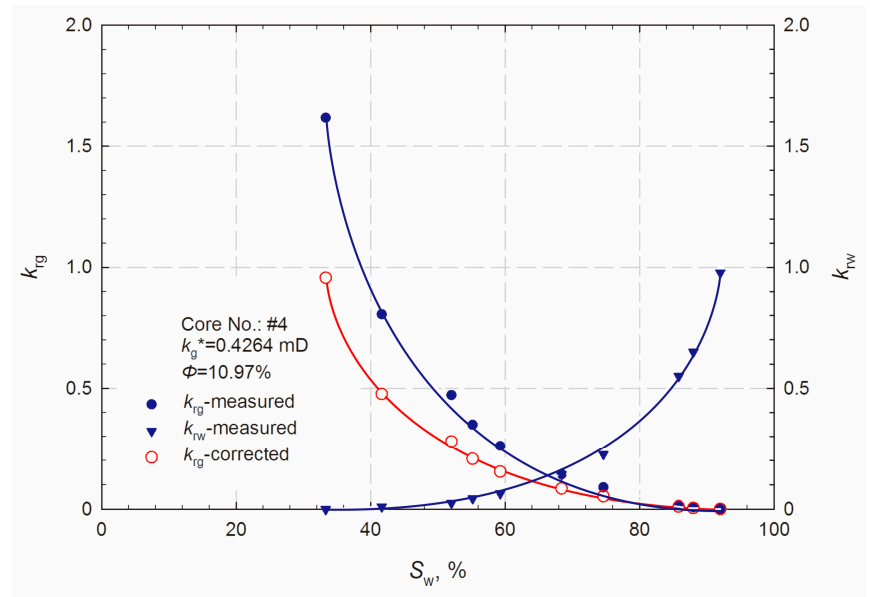

Figure 6. Gas-water relative permeability with and without Klinkenberg correction.

The uncalibrated gas relative permeability at the irreducible water saturation is larger than 1.0 as shown in Figure 6. This means that the effective gas phase permeability at $S_{w i}=33.3 \%$ is larger than the absolute permeability due to the slippage effect. Subsequently, Equation (7) was utilized to correct the effective gas phase permeability and determine the Klinkenberg permeability under different water saturations. The corrected gas relative permeability has also been plotted in Figure 6 . It is worthy to note that the gas relative permeability at the irreducible water saturation reduces to be less than 1.0 after the correction. This phenomenon demonstrates that the gas relative permeability may be overestimated if the slippage effect is not considered during the process of determining the relative permeability.

\subsection{Gas-Water Relative Permeability Sensitivity Analysis}

With the assistance of the unsteady-state displacement experiments and the newly proposed correlations, the sensitivity analyses are conducted to investigate the impacts of $k_{g}$, confining pressure, and temperature on the gas-water relative permeability. As shown in Table 2, a total of eight unsteady-state displacement experiments have been conducted on five core samples in Group 2. The core samples \#13-15 are used for evaluating the effect of $k_{g}$ while core samples \#16 and \#17 are employed to identify the influence of confining pressure and temperature on the gas-water relative permeability, respectively.

Table 2. Experimental conditions for the sensitivity analysis experiments

\begin{tabular}{ccccc}
\hline Core No. & $\boldsymbol{k}_{\boldsymbol{g}^{*}}^{*} \mathbf{m D}$ & Confining Pressure, MPa & Temperature, ${ }^{\circ} \mathbf{C}$ & Pressure Drop, MPa \\
\hline 13 & 0.1418 & 30 & 90 & 8 \\
\hline 14 & 0.2986 & 30 & 90 & 8 \\
\hline 15 & 0.7312 & 30 & 90 & 8 \\
\hline \multirow{2}{*}{16} & \multirow{2}{*}{2.8730} & 30 & 90 & 4 \\
& & 50 & 90 & 4 \\
\hline \multirow{2}{*}{17} & \multirow{2}{*}{0.2280} & 30 & 25 & 4 \\
& & 30 & 50 & 4 \\
\hline
\end{tabular}

\subsubsection{Effect of $k_{g}$}

In an attempt to investigate the effect of $k_{g}$, the confining pressure and temperature have been kept constant. The gas-water relative permeability with different $k_{g}$ has been experimentally obtained and shown in Figure 7. Note that the effective gas phase permeability has been correspondingly corrected by using the developed correlations with respect to the experimental conditions. It can be found that 
both the irreducible water saturation and the critical gas saturation (i.e., the minimum gas saturation when the gas starts to flow) decrease due to the increased permeabilities (i.e., $k_{g}$ ), resulting in an expanded mobile water range. In addition, the water relative permeability at critical gas saturation is relatively large for high permeability cores and small for low permeability cores. The thin section analyses results of the core samples \#13 and \#15 have been collected and shown in Figure 8. As can be seen, the pores-throats connectivity of the core sample \#15 is much better than that of the core sample \#13. Such a difference makes its contribution to not only the permeability but also the flow capacity of water and gas saturated in the pore structure.

The gas relative permeability can be interfered by water saturation to a different extent. The dependence of gas phase permeability on the irreducible water saturation has been addressed by Wall et al. (1982) [20]. They indicated that water saturation may be one of the most critical factors for gas recovery. Rushing et al. (2003) measured the effect of connate water saturation (5-40\%) on the gas relative permeability and demonstrated that gas relative permeability intends to decrease as connate water saturation increases [18]. The effect of mobile water on the gas relative permeability as shown in Figure 7 illustrates the same phenomenon as well. The gas relative permeability of the core sample \#13 is higher than that of the core sample \#15 at the same water saturation, although $k_{g}$ of core sample \#13 is lower than that of the core sample \#15. This is because more mobile water is involved in the core sample \#15 which has lower irreducible water saturation. It demonstrates that the reduced gas relative permeability by the presence of mobile water is much larger than that caused by the irreducible water even if their values are identical.

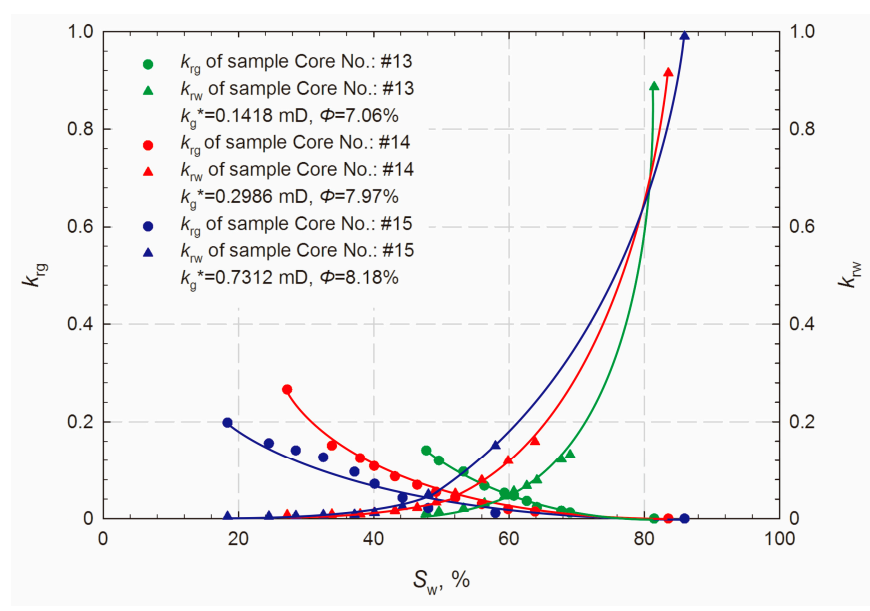

Figure 7. Effect of permeability on gas-water relative permeability.

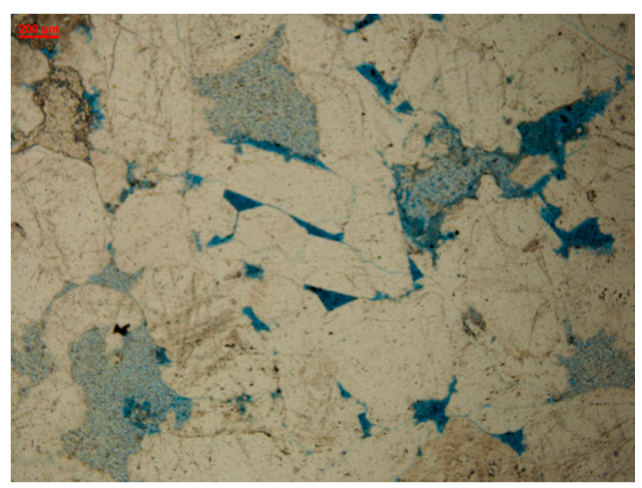

(a)

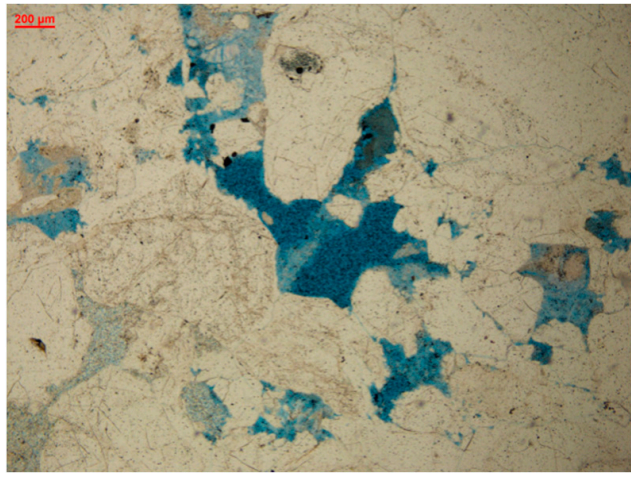

(b)

Figure 8. Pore structure illustrated by thin section analysis results of (a) core sample \#13 and (b) core sample \#15. 


\subsubsection{Effect of Confining Pressure}

Figure 9 illustrates the different responses of gas and water relative permeability to confining pressure changes. Although a high confining pressure may lead to dramatic permeability reduction, the gas and water relative permeability are impacted in different manners. Firstly, the irreducible water saturation increases under the condition of a larger confining pressure. This means partially interconnected pores may be closed due to lower throat size and higher capillary pressure, generating more irreducible water locked in the core samples. Secondly, the critical gas saturation also increases with the increased confining pressure. Such a change is attributed to the reduced pore and throat size as well. However, the sensitivity of water relative permeability to the confining pressure is stronger than that of the gas relative permeability, resulting in that the reduction of effective water phase permeability is larger than the reduction of effective gas phase permeability, which is consistent with the changes of gas and water relative permeability resulted from increasing the confining pressure. As shown in Figure 9, the gas relative permeability increases and the water relative permeability decreases while the confining pressure is increased from 30.0 MPa to 50.0 MPa. This is in line with the observations of changes in connate water saturation and critical gas saturation.

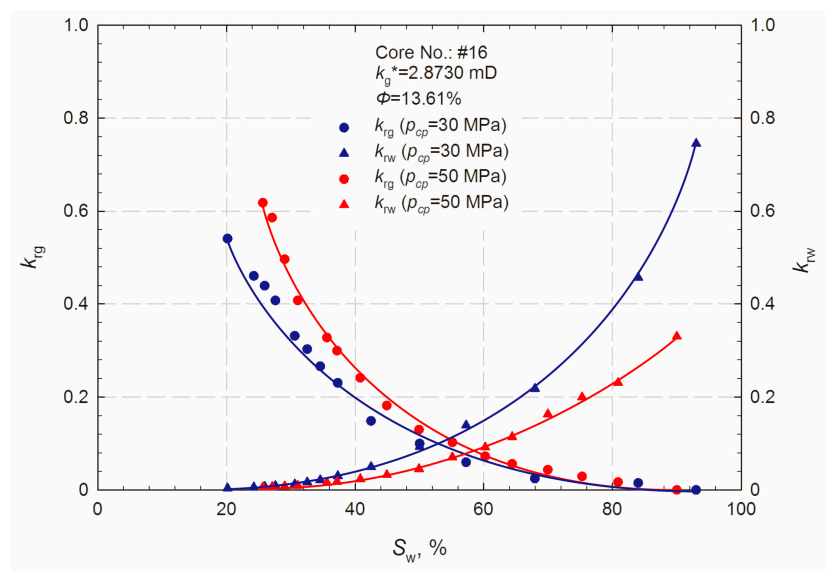

Figure 9. Effect of confining pressure on gas-water relative permeability.

\subsubsection{Effect of Temperature}

According to Figure 3, the viscosity of the synthetic brine is more sensitive to temperature compared to the nitrogen. The viscosity of the synthetic brine may reduce by two-thirds while the viscosity of nitrogen increases by approximately $20 \%$, provided that the temperature is raised up from $25^{\circ} \mathrm{C}$ to $90^{\circ} \mathrm{C}$. The gas-water relative permeability at various temperatures has been experimentally measured and depicted in Figure 10. The effective gas phase permeability decreases and the effective water phase permeability increases due to distinguishable viscosity changes of the nitrogen and the synthetic water with respect to temperature. In addition, the irreducible water saturation reduces when the experimental temperature is raised up. This generates more mobile water in the core samples, resulting in further reduction of the effective permeability as aforementioned.

It has been addressed that the Klinkenberg permeability is independent of experimental temperatures if there is only connate water in the core samples [21,22]. The effective gas phase permeability might be influenced by the experimental temperature during the two-phase displacement experiments, although the temperature-induced differences between gas relative permeabilities are smaller than that between water relative permeabilities. This demonstrates that it is imperative and essential to consider the effect of temperature on the gas-water relative permeability measurements. 


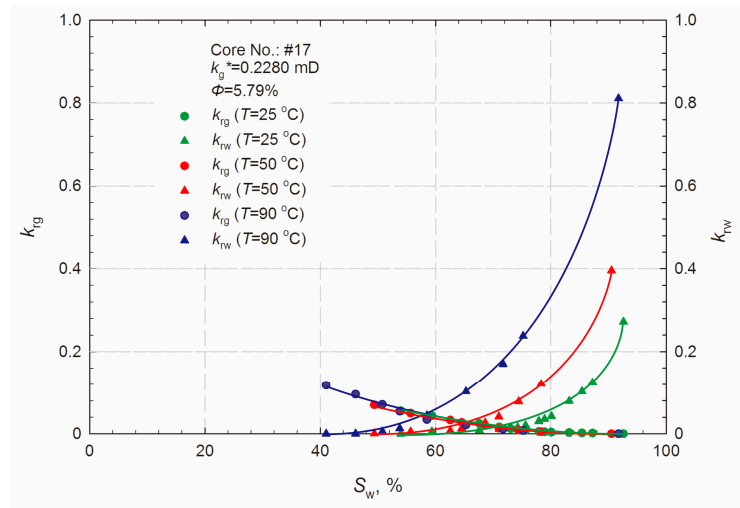

Figure 10. Effect of temperature on gas-water relative permeability.

\section{Conclusions}

The gas-water relative permeability has been calibrated by considering the slippage effect under various conditions. New linear correlations have been proposed to determine the Klinkenberg permeability by using gas-measured permeability at ambient, high-temperature, and high-temperaturehigh-confining-pressure conditions. The effects of experimental conditions can be illustrated by the coefficients of the linear correlation. Note that one correlation has been used for describing the linear relationship for both the ambient and high-temperature conditions since the Klinkenberg permeability is independent of the temperature. In addition, it has been demonstrated that the gas relative permeability may be overestimated if the slippage effect is not handled during the process of determining the effective gas phase permeability. With the assistance of the newly proposed correlations, the sensitivities of gas-water relative permeability have been experimentally investigated by considering various gas permeabilities, experimental temperatures, and confining pressures. It has been found that various gas-measured permeabilities lead to different irreducible water saturation, critical gas saturation, and mobile water saturation, which dramatically affect the effective gas and water phase permeability. It is also demonstrated that the reduced gas relative permeability by the presence of mobile water is much larger than that caused by the irreducible water even if their values are identical. Moreover, the sensitivity of water relative permeability to the confining pressure is stronger than that of the gas relative permeability. The gas relative permeability decreases and the water relative permeability increases, provided that the temperature is increased. This is attributed to the synergistic effect of the fluid viscosity and the slippage factor, implying that it is imperative and essential to consider the effect of temperature on the gas-water relative permeability measurements.

Acknowledgments: The authors gratefully acknowledge the financial support from National Natural Science Foundation of China (Grant No. 51404282).

Author Contributions: Guangfeng Liu and Yang Lu conceived and designed the experiments; Bo Feng, Yu Xia, and Qimeng Zhao cooperatively performed the experiments; Zhaoqi Fan and Siying Li analyzed the data and wrote the paper.

Conflicts of Interest: The authors declare no conflict of interest.

\section{References}

1. Arora, A.; Bachle, A. Storage of Natural Gas by Adsorption Process. In Proceedings of the SPE/IATMI Asia Pacific Oil and Gas Conference and Exhibition, Nusa Dua, Indonesia, 20-22 October 2015. SPE 176129.

2. Economides, M.; Oligney, R.; Valko, P. Unified Fracture Design: Bridging the Gap between Theory and Practice; Orsa Press: Alvin, TX, USA, 2002.

3. Daal, J.; Economides, M.J. Optimization of Hydraulically Fractured Wells in Irregularly Shaped Drainage Areas. In Proceedings of the SPE International Symposium and Exhibition on Formation Damage Control, Lafayette, LA, USA, 15-17 February 2006; SPE 98047. 
4. Nehring, R. Growing and Indispensable: The Contribution of Production. In Understanding, Exploring, and Developing Tight-Gas Sands; Cumella, S.P., Shanley, K.W., Camp, W.K., Eds.; The American Association of Petroleum Geologists: Tulsa, OK, USA, 2008; Volume 3, pp. 5-12.

5. Dai, J.; Ni, Y.; Wu, X. Tight Gas in China and Its Significance in Exploration and Exploitation. Pet. Explor. Dev. 2012, 39, 277-284. [CrossRef]

6. Byrnes, A.P.; Sampath, K.; Randolph, P.L. Effect of Pressure and Water Saturation on the Permeability of Western Tight Sandstones. In Proceedings of the 5th Annual U.S. Department of Energy Symposium on Enhanced Oil and Gas Recovery, Tulsa, OK, USA, 22-26 August 1979.

7. Ward, J.S.; Morrow, N.R. Capillary Pressure and Gas Relative Permeabilities of Low Permeability Sandstone. SPE Form. Eval. 1987, 2, 345-356. [CrossRef]

8. Kamath, J.; Boyer, R.E. Critical Gas Saturation and Supersaturation in Low Permeability Rocks. SPE Form. Eval. 1995, 10, 247-254. [CrossRef]

9. Shanley, K.W.; Cluff, R.M.; Robinson, J.W. Factors Controlling Prolific Gas Production from Low-Permeability Sandstone Reservoirs: Implications for Resource Assessment, Prospect Development, and Risk Analysis. AAPG Bull. 2004, 88, 1083-1121. [CrossRef]

10. Wang, Y.; Chen, Z.; Morah, V.; Knabe, R.J.; Appel, M. Gas-Phase Relative Permeability Characterization on Tight-Gas Samples. Petrophysics 2012, 53, 393-400.

11. Klinkenberg, L. The permeability of porous media to liquids and gases. In Proceedings of the Drilling and Production Practice, New York, NY, USA, 1 January 1941.

12. Fulton, P.F. The Effect of Gas Slippage on Relative Permeability Measurements. Prod. Mon. 1951, 15, 14-19.

13. Estes, R.K.; Fulton, P.F. Gas Slippage and Permeability Measurements. J. Pet. Technol. 1956, 8, 69-73. [CrossRef]

14. Sampath, K.; Keighin, C.W. Factors Affecting Gas Slippage in Tight Sandstones of Cretaceous Age in the Uinta Basin. J. Pet. Technol. 1982, 34, 2715-2720. [CrossRef]

15. Thompson, A.H.; Raschke, R.A. Estimation of Absolute Permeability from Capillary Pressure Measurements. In Proceedings of the SPE Annual Technical Conference and Exhibition, Dallas, TX, USA, 27-30 September 1987; SPE 16794.

16. Li, S.; Dong, M.; Li, Z. Measurement and Revised Interpretation of Gas Flow Behavior in Tight Reservoir Cores. J. Pet. Sci. Eng. 2009, 65, 81-88. [CrossRef]

17. Thomas, R.D.; Ward, D.C. Effect of Overburden Pressure and Water Saturation on Gas Permeability of Tight Sandstone Cores. J. Pet. Technol. 1972, 24, 120-124. [CrossRef]

18. Rushing, J.A.; Newsham, K.E.; Van Fraassen, K.C. Measurement of the Two-Phase Gas Slippage Phenomenon and Its Effect on Gas Relative Permeability in Tight Gas Sands. In Proceedings of the SPE Annual Technical Conference and Exhibition, Denver, CO, USA, 5-8 October 2003. SPE 84297.

19. Lei, G.; Dong, P.; Wu, Z.; Mo, S.; Gai, S.; Zhao, C.; Liu, Z.K. A Fractal Model for the Stress-Dependent Permeability and Relative Permeability in Tight Sandstones. J. Can. Pet. Technol. 2015, 54, 36-48. [CrossRef]

20. Walls, J.D.; Nur, A.M.; Bourbie, T. Effects of Pressure and Partial Water Saturation on Gas Permeability in Tight Sands: Experimental Results. J. Pet. Technol. 1982, 34, 930-936. [CrossRef]

21. Wei, K.K.; Morrow, N.R.; Brower, K.R. Effect of Fluid, Confining Pressure, and Temperature on Absolute Permeabilities of Low-Permeability Sandstones. SPE Form. Eval. 1986, 1, 413-423. [CrossRef]

22. Li, K.; Horne, R.N. Gas Slippage in Two-Phase Flow and the Effect of Temperature. In Proceedings of the SPE Western Regional Meeting: Bakersfield, CA, USA, 26-30 March 2001. SPE 68778.

23. Liu, G.; Bai, Y.; Fan, Z.; Gu, D. Determination of Klinkenberg Permeability Conditioned to Pore-Throat Structures in Tight Formations. Energies 2017, 10, 1575. [CrossRef]

(C) 2018 by the authors. Licensee MDPI, Basel, Switzerland. This article is an open access article distributed under the terms and conditions of the Creative Commons Attribution (CC BY) license (http:/ / creativecommons.org/licenses/by/4.0/). 